\title{
Real-World Rates of Bleeding, Factor VIII Use, and Quality of Life in Individuals with Severe Haemophilia A Receiving Prophylaxis in a Prospective, Noninterventional Study
}

\author{
Gili Kenet ${ }^{1, *}$ (1), Yeu-Chin Chen ${ }^{2}$, Gillian Lowe ${ }^{3}$, Charles Percy ${ }^{3}$, Huyen Tran ${ }^{4}$, Annette von Drygalski ${ }^{5}$, \\ Marc Trossaërt ${ }^{6}$, Mark Reding ${ }^{7}$, Johannes Oldenburg ${ }^{8}{ }^{(}$, Maria Eva Mingot-Castellano ${ }^{9}{ }^{\circ}$, Young-Shil Park ${ }^{10}{ }^{\circ}$, \\ Flora Peyvandi ${ }^{11,12} \oplus^{10}$, Margareth C. Ozelo ${ }^{13}$, Johnny Mahlangu ${ }^{14}$, Jennifer Quinn ${ }^{15}$, Mei Huang ${ }^{16}$, \\ Divya B. Reddy ${ }^{16}$ (i) and Benjamin Kim ${ }^{16}$
}

check for

updates

Citation: Kenet, G.; Chen, Y.-C.;

Lowe, G.; Percy, C.; Tran, H.; von

Drygalski, A.; Trossaërt, M.; Reding,

M.; Oldenburg, J.; Mingot-Castellano,

M.E.; et al. Real-World Rates of

Bleeding, Factor VIII Use, and

Quality of Life in Individuals with

Severe Haemophilia A Receiving

Prophylaxis in a Prospective,

Noninterventional Study. J. Clin. Med.

2021, 10, 5959. https://doi.org/

$10.3390 /$ jcm10245959

Academic Editor: Paul Monahan

Received: 12 November 2021

Accepted: 15 December 2021

Published: 18 December 2021

Publisher's Note: MDPI stays neutral with regard to jurisdictional claims in published maps and institutional affiliations.

Copyright: (c) 2021 by the authors. Licensee MDPI, Basel, Switzerland. This article is an open access article distributed under the terms and conditions of the Creative Commons Attribution (CC BY) license (https:// creativecommons.org/licenses/by/ $4.0 /)$.
1 The National Hemophilia Center, Amalia Biron Research Institute of Thrombosis and Hemostasis, Sheba Medical Center, Tel Aviv University, Tel Hashomer, Tel Aviv-Yafo 52621, Israel

2 Haemophilia Care and Research Center, Tri-Service General Hospital, National Defense Medical Center, Taipei 11490, Taiwan; yeuchin99@gmail.com

3 West Midlands Comprehensive Care Haemophilia Centre, Queen Elizabeth Hospital, Birmingham B15 2TH, UK; gillian.lowe@uhb.nhs.uk (G.L.); charles.percy@uhb.nhs.uk (C.P.)

4 Haemophilia Treatment Centre, Haemostasis \& Thrombosis Unit, The Alfred Hospital, Melbourne, VIC 3004, Australia; huyen.tran@monash.edu

5 Department of Molecular Medicine, Scripps Research Institute, La Jolla, CA 92037, USA; avondrygalski@ucsd.edu

6 Centre Régional de Traitement des Hémophiles, CHU de Nantes, 44093 Nantes, France; marc.trossaert@chu-nantes.fr

7 Center for Bleeding and Clotting Disorders, University of Minnesota, Minneapolis, MN 55454, USA; redin002@umn.edu

8 Center for Rare Diseases and Institute of Experimental Haematology and Transfusion Medicine, University Hospital Bonn, 53127 Bonn, Germany; johannes.oldenburg@ukbonn.de

9 Regional University Hospital, Carlos Haya, 29010 Málaga, Spain; memingot@gmail.com

10 Kyung Hee University Hospital at Gangdong, Seoul 134-727, Korea; pysped@khu.ac.kr

11 Fondazione IRCCS Ca' Granda Ospedale Maggiore Policlinico, Angelo Bianchi Bonomi Hemophilia and Thrombosis Center and Fondazione Luigi Villa, 20122 Milan, Italy; flora.peyvandi@unimi.it

12 Department of Pathophysiology and Transplantation, Università degli Studi di Milano, 20122 Milan, Italy

13 Hemocentro UNICAMP, Department of Internal Medicine, School of Medical

Sciences, University of Campinas, Campinas 13083-878, SP, Brazil; margaret@unicamp.br

14 Hemophilia Comprehensive Care Center, Charlotte Maxeke Johannesburg Academic Hospital, University of the Witwatersrand and NHLS, Johannesburg 2193, South Africa; johnny.mahlangu@nhls.ac.za

15 BioMarin Pharmaceutical UK Ltd., London WC1A 2SL, UK; jennifer.quinn@bmrn.com

16 BioMarin Pharmaceutical Inc., Novato, CA 94949, USA; Mei.Huang@bmrn.com (M.H.); divya.reddy@bmrn.com (D.B.R.); ben.kim@bmrn.com (B.K.)

* Correspondence: Gili.kenet@sheba.health.gov.il

Abstract: Regular prophylaxis with exogenous factor VIII (FVIII) is recommended for individuals with severe haemophilia A (HA), but standardised data are scarce. Here, we report real-world data from a global cohort. Participants were men $\geq 18$ years old with severe HA (FVIII $\leq 1 \mathrm{IU} / \mathrm{dL}$ ) receiving regular prophylaxis with FVIII. Participants provided 6 months of retrospective data and were prospectively followed for up to 12 months. Annualised bleeding rate (ABR) and FVIII utilisation and infusion rates were calculated. Differences between geographic regions were explored. Of 294 enrolled participants, 225 (76.5\%) completed $\geq 6$ months of prospective follow-up. Pre-baseline and on-study, the median (range) ABR values for treated bleeds were 2.00 (0-86.0) and 1.85 (0-37.8), respectively; the median (range) annualised FVIII utilisation rates were 3629.0 (1008.5-13541.7) and 3708.0 (1311.0-14633.4) IU/kg/year, respectively; and the median (range) annualised FVIII infusion rates were 120.0 (52.0-364.0) and 122.4 (38.0-363.8) infusions/year, respectively. The median (range) Haemo-QoL-A Total Score was 76.3 (9.4-100.0) $(n=289)$, ranging from 85.1 in Australia to 67.7 in South America. Physical Functioning was the most impacted Haemo-QoL-A domain in 4/6 geographic regions. Despite differences among sites, participants reported bleeding requiring treatment 
and impaired physical functioning. These real-world data illustrate shortcomings associated with FVIII prophylaxis for this global cohort of individuals with severe HA.

Keywords: haemophilia A; noninterventional study; FVIII prophylaxis

\section{Introduction}

Haemophilia A (HA) is an X-linked recessive bleeding disorder caused by mutations in the gene that codes for factor VIII (FVIII) protein, an essential cofactor in the coagulation pathway. The estimated prevalence of HA is 17.1 per 100,000 males, with about one-third affected by severe HA, defined as FVIII activity $<1 \mathrm{IU} / \mathrm{dL}$ [1,2]. Clinical manifestations of severe HA include frequent spontaneous bleeding episodes, predominantly in joints and soft tissues, which can lead to debilitating multiple-joint arthropathies and substantially increased risk of death [3]. Regular prophylaxis is recommended for individuals with severe HA [3]. Although recent advances in haemophilia treatment and management have dramatically increased quality of life (QoL), individuals with severe HA still experience bleeding events [4], indicating an unfulfilled need for greater haemostatic control in this population. These unmet needs in those receiving prophylactic FVIII replacement therapy are incompletely characterised on an individual and population level [5,6]. Standardised data on bleeding, FVIII use, and QoL in the setting of routine clinical practice for patients on prophylaxis are needed to better understand the burden of both severe HA and the prophylactic treatment approach.

This multinational, prospective, noninterventional study collected standardised real-world data on bleeding episodes, haemophilia medication use, and health-related QoL from a global, heterogeneous population of participants with severe HA on currently available FVIII prophylaxis. This study was also a run-in for the sponsor's phase 3 gene therapy studies (Clinicaltrials.gov NCT03370913/EudraCT 2017-003215-19, NCT03392974/EudraCT 2017-003573-34).

\section{Materials and Methods}

\subsection{Study Design and Participants}

This prospective, multicentre, multinational, noninterventional, longitudinal study was conducted in compliance with local regulations, International Conference on Harmonisation Guidelines for Good Clinical Practice, and the Declaration of Helsinki; ethics committees or review boards at all participating sites approved the protocol (Supplementary S1). Participating sites were located in Australia, Belgium, Brazil, France, Germany, Israel, Italy, South Africa, South Korea, Spain, Taiwan, the UK, and the US. Sites were selected based on selective global outreach to haemophilia treatment centres that expressed interest in participating in a future gene therapy trial and were deemed to be capable of doing so. Participants were males $\geq 18$ years old with severe HA (FVIII activity $\leq 1 \mathrm{IU} / \mathrm{dL}$ ) continuously treated with prophylactic exogenous FVIII for $\geq 6$ months [2].

Planned enrolment was up to 250 participants followed for $\geq 6$ months and $\leq 12$ months. After 6 months, potentially eligible participants could be screened for entry into a phase 3 interventional study of valoctocogene roxaparvovec (Clinicaltrials.gov NCT03370913/EudraCT 2017-003215-19, NCT03392974/EudraCT 2017-003573-34). To be eligible, participants had to have received prophylactic FVIII therapy for $\geq 6$ months prior to study entry and been treated/exposed to FVIII concentrates or cryoprecipitate for $\geq 150$ exposure days. Participants could not have a history of detectable FVIII inhibitors. After being initially eligible for enrolment, participants positive for human immunodeficiency virus (HIV) infection were excluded by a protocol amendment—-secondary to the development of elevated liver enzyme levels by an HIV-positive participant who was receiving a combination of highly active antiretroviral therapy (HAART) and valoctocogene roxaparvovec-out of caution for the long-term liver health of HIV-positive participants receiving HAART who may be interested in receiving gene therapy. Additional exclusion criteria, including significant 
liver dysfunction, chronic or active hepatitis B, and active hepatitis C, are described in detail in (Supplementary S2). High-quality historical documentation concerning bleeding and exogenous FVIII usage over the previous 6 months was required. Retrospectively collected pre-baseline data were compared to and combined with data collected during the study period. There were no minimum requirements of annualised bleeding rates, either before or during this study, that could impact participants' eligibility for the future gene therapy trial. However, the possibility of future enrolment in gene therapy a trial may have been a motivating factor for some participants to enrol in this study.

Pre-existing host humoral and cellular immunity against the AAV capsid are known to negatively affect the efficacy of AAV-vector-based gene therapies [7]; thus, participants were also screened for pre-existing adeno-associated virus 5 (AAV5). Although antibody status did not impact eligibility for this trial, participants positive for anti-AAV5 antibodies were not eligible for enrolment in the subsequent gene therapy trial.

Study procedures included the review and entry of bleeding episode and haemophilia medication data on at least a monthly basis, as well as the collection of concomitant medications, adverse events (AEs), serious AEs (SAEs), and interim medical history at each visit or during telephone calls on at least a monthly basis. Except for screening/baseline and end-of-study visits, all other study visits occurred according to participants' local standard of care. No clinical intervention or study drug was provided.

\subsection{Study Assessments and Endpoints}

After enrolment, participants reported bleeding episodes and haemophilia medication data on a weekly basis for the duration of the study. Details of each bleeding episode were captured, including start date/time, type (e.g., joint or muscle), location, and whether there was preceding trauma or ensuing treatment. Specific reporting of all administered haemophilia medications was required, including start/date time, product name, dose, and reason for use (e.g., usual prophylaxis, one-time prophylaxis, or treatment for bleed). As the prescribed frequency of usual FVIII prophylaxis was not captured, the manual review of listings was required to adjudicate the prescribed frequency of infusions and assess adherence. The primary clinical endpoint was the annualised number of bleeding episodes (annualised bleeding rate (ABR)) requiring exogenous FVIII replacement treatment. Secondary clinical endpoints included the annualised utilisation (IU $/ \mathrm{kg} / \mathrm{yr}$ ) and infusion rate (count/yr) of exogenous FVIII replacement therapy. Participants also completed 4 patientreported outcome (PRO) assessments on day 1, including the haemophilia-specific healthrelated quality of life questionnaire for adults (Haemo-QoL-A) [8,9], EQ-5D-5L [10,11], Haemophilia Activities List (HAL) [12], and Work Productivity and Activity Impairment plus Classroom Impairment Questions: Haemophilia Specific (WPAI+CIQ:HS) [13,14], as described in Supplementary S2. Safety assessments consisted of monitoring AEs (coded using the Medical Dictionary for Regulatory Activities v20.1) and measuring vital signs and haematology, clinical chemistry, and urinalysis variables.

\subsection{Statistical Analysis}

Baseline and safety analyses included all enrolled participants. Bleeding and FVIII usage were analysed for those with $\geq 6$ months of on-study data (6-Month Analysis Population). ABR was calculated using only treated bleeds for the primary analysis; bleeds due to surgery/procedure were not included. ABR was defined as number of bleeding episodes during the calculation period/total number of calculation period days $\times 365.25$. ABR and FVIII usage rates were determined for the 6 months before day 1 (pre-baseline), 6 months after day 1 (on-study), and total duration (pre-baseline and on-study). Supportive analyses included all bleeds (treated and non-treated), joint bleeds, problem joint bleeds, spontaneous bleeds, and traumatic bleeds. Results were also evaluated by prophylaxis type (standard half-life (SHL), extended half-life (EHL), or plasma-derived (PD)) and geographic regions in which the sites were located to provide a more nuanced understanding of the data. The regional analysis included the following groups: Australia (6 sites), Eu- 
rope/Middle East (3 sites in Belgium, 6 in France, 2 in Germany, 1 in Israel, 2 in Italy, 3 in Spain, and 9 in the UK), Africa (2 sites in South Africa), North America (16 sites in the US), South America (1 site in Brazil), and East Asia (3 sites in South Korea and 5 in Taiwan). All variables were descriptively summarised. As the trial was not designed to test a statistical hypothesis, power analyses to determine sample size were not performed.

\section{Results}

\subsection{Baseline Characteristics}

Of the 370 participants who were screened, 28 did not meet screening criteria and an additional 48 (13\%) passed screening but did not enrol (Figure 1). Of these 48 participants, 47 were positive for AAV5 antibodies at screening, thus precluding their participation in the subsequent phase 3 gene therapy trial and likely impacting their decision not to enrol. Of 294 enrolled participants, 225 (76.5\%) completed $\geq 6$ months on-study and were included in the 6-Month Analysis Population.

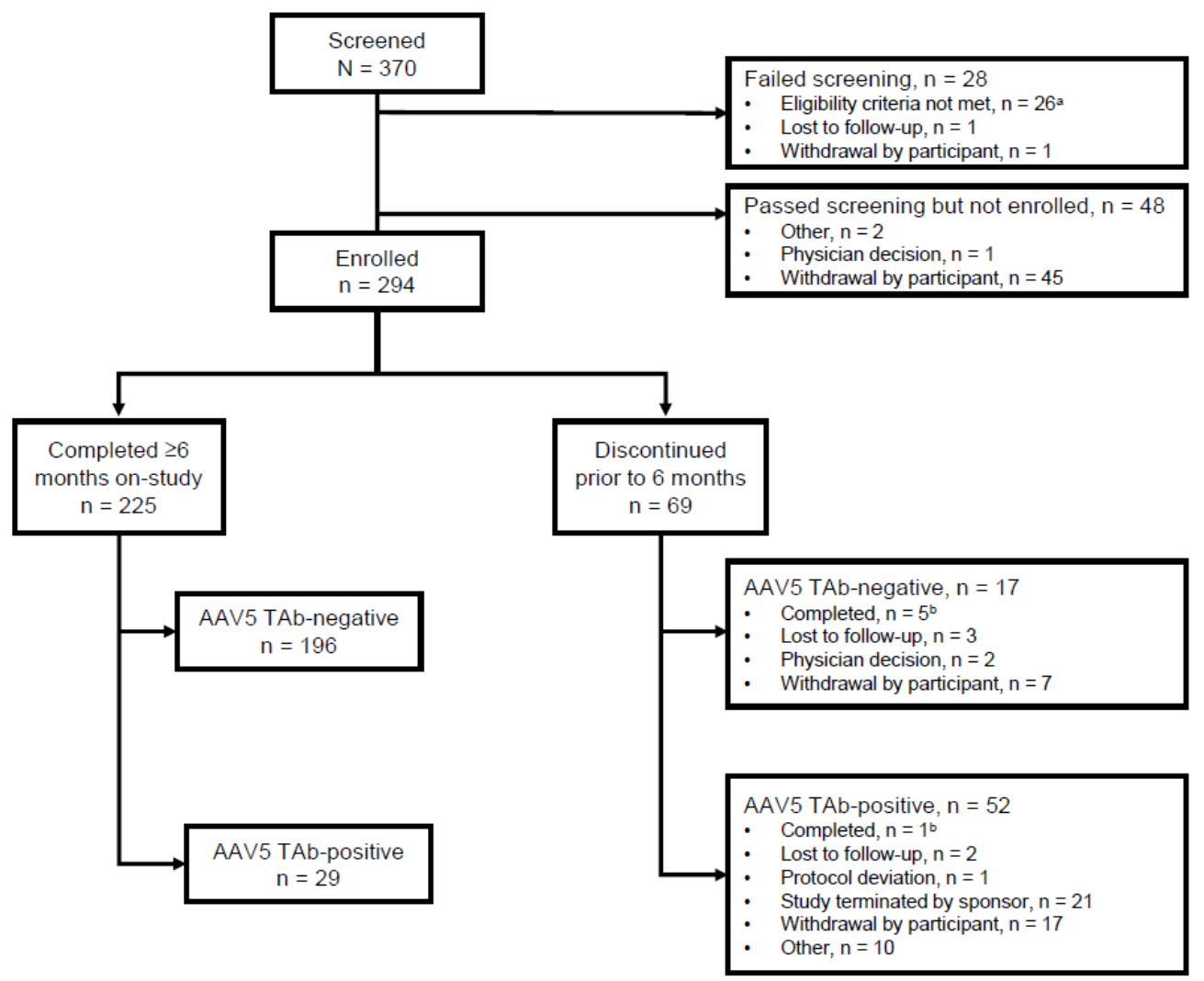

Figure 1. Patient disposition. ${ }^{\text {a }}$ Reasons for screen failure: no history of FVIII inhibitor and results from a Bethesda assay, $n=8$; significant liver dysfunction with abnormal laboratory results, $n=3$; active hepatitis $C, n=6$; chronic or active hepatitis $B, n=1$; concurrent enrolment in another clinical study, $n=2$; ability to comply with protocol requirements per Investigator, $n=2$; male $\geq 18$ years of age with residual FVIII $\leq 1, n=1$; must have been on prophylaxis FVIII for $\geq 6$ months prior, $n=4 .{ }^{\mathrm{b}}$ Completing 6 months on-study was not required for participants not rolling over into the interventional study. AAV5 TAb, adeno-associated virus vector total antibody; FVIII, factor VIII.

Median (range) age at enrolment was 31.0 (18.0-71.0) years, including $85.0 \%$ who were $\leq 50$ years old and $95.6 \%$ who were $<65$ years old. All participants were male, and $62.9 \%$ were white (Table 1). Overall, $34.4 \%$ of participants reported $\geq 1$ problem joint, defined as a joint with chronic joint pain, chronic synovitis, haemophilic arthropathy, limited motion, or recurrent bleeding [15-17]. At baseline, among all enrolled participants, 198 (67.3\%) reported a history of musculoskeletal and connective tissue disorders, including 139 (47.3\%) with haemophilic arthropathy. Knee arthroplasty was reported by 41 (13.9\%) participants. 
Table 1. Patient demographics and baseline characteristics.

\begin{tabular}{|c|c|c|c|c|c|c|c|}
\hline Parameter & $\begin{array}{l}\text { Australia } \\
(n=27)\end{array}$ & $\begin{array}{c}\text { Europe/ } \\
\text { Middle East }{ }^{\text {a }} \\
\quad(n=95)\end{array}$ & $\begin{array}{c}\text { South } \\
\text { America } \\
(n=54)\end{array}$ & $\begin{array}{l}\text { East Asia }{ }^{c} \\
\quad(n=32)\end{array}$ & $\begin{array}{l}\text { North } \\
\text { America } \\
(n=48)\end{array}$ & $\begin{array}{l}\text { Africa } \\
(n=38)\end{array}$ & $\begin{array}{c}\text { Overall } \\
\text { Enrolled } \\
\text { Population } \\
(N=294)\end{array}$ \\
\hline $\begin{array}{l}\text { Age at enrolment, } \\
\text { median (min, max) years }\end{array}$ & $\begin{array}{c}31.0 \\
(18.0,71.0)\end{array}$ & $\begin{array}{c}33.0 \\
(18.0,70.0)\end{array}$ & $\begin{array}{c}27.0 \\
(18.0,47.0)\end{array}$ & $\begin{array}{c}40.0 \\
(20.0,66.0)\end{array}$ & $\begin{array}{c}32.0 \\
(19.0,70.0)\end{array}$ & $\begin{array}{c}28.0 \\
(18.0,67.0)\end{array}$ & $\begin{array}{c}31.0 \\
(18.0,71.0)\end{array}$ \\
\hline Male sex, $n(\%)$ & $27(100.0)$ & $95(100.0)$ & $54(100.0)$ & $32(100.0)$ & $48(100.0)$ & $38(100.0)$ & $294(100.0)$ \\
\hline \multicolumn{8}{|l|}{ Race, $n(\%)$} \\
\hline Asian & $2(7.4)$ & $6(6.3)$ & 0 & $32(100.0)$ & $2(4.2)$ & 0 & $42(14.3)$ \\
\hline Black or African American & 0 & $1(1.1)$ & $10(18.5)$ & 0 & $5(10.4)$ & $14(36.8)$ & $30(10.2)$ \\
\hline White & $24(88.9)$ & $65(68.4)$ & $44(81.5)$ & 0 & $39(81.3)$ & $13(34.2)$ & $185(62.9)$ \\
\hline Other & $1(3.7)$ & 0 & 0 & 0 & 0 & 0 & $1(0.3)$ \\
\hline Not provided ${ }^{\mathrm{f}}$ & 0 & $23(24.2)$ & 0 & 0 & $2(4.2)$ & $11(28.9)$ & $36(12.2)$ \\
\hline Hispanic or Latino ethnicity & $1(3.7)$ & $2(2.1)$ & 0 & 0 & $1(2.1)$ & 0 & $4(1.4)$ \\
\hline Weight, mean (SD), kg & $83.3(18.1)$ & $77.4(14.9)$ & $78.9(20.4)$ & $61.8(11.0)$ & $84.5(19.6)$ & $67.9(18.7)$ & $79.0(18.1)$ \\
\hline History of hepatitis $\mathrm{B} g, n(\%)$ & $3(11.1)$ & $20(21.1)$ & $1(1.9)$ & $8(25.0)$ & 7 (14.6) & $5(13.2)$ & $44(15.0)$ \\
\hline History of hepatitis $\mathrm{C} g, n(\%)$ & $12(44.4)$ & $43(45.3)$ & $12(22.2)$ & $20(62.5)$ & $24(50.0)$ & $7(18.4)$ & $118(40.1)$ \\
\hline History of HIV, $n(\%)$ & 0 & $4(4.2)$ & 0 & 0 & $6(12.5)$ & 0 & $10(3.4)$ \\
\hline $\begin{array}{c}\text { Participants with problem } \\
\text { joints } \mathrm{h}, n(\%)\end{array}$ & $9(33.3)$ & $42(44.2)$ & $5(9.3)$ & $18(56.3)$ & $20(41.7)$ & 7 (18.4) & $101(34.4)$ \\
\hline \multicolumn{8}{|l|}{$\begin{array}{l}\text { Number of problem } \\
\text { joints } \mathrm{h}, n(\%)\end{array}$} \\
\hline 0 & $18(66.7)$ & $53(55.8)$ & $49(90.7)$ & $14(43.8)$ & $28(58.3)$ & $31(81.6)$ & $193(65.6)$ \\
\hline 1 & $3(11.1)$ & $14(14.7)$ & $5(9.3)$ & $11(34.4)$ & $6(12.5)$ & $6(15.8)$ & $45(15.3)$ \\
\hline 2 & $3(11.1)$ & $9(9.5)$ & 0 & $5(15.6)$ & $3(6.3)$ & $1(2.6)$ & $21(7.1)$ \\
\hline 3 & $2(7.4)$ & $8(8.4)$ & 0 & $2(6.3)$ & $4(8.3)$ & 0 & $16(5.4)$ \\
\hline$>3$ & $1(3.7)$ & 11 (11.6) & 0 & 0 & 7 (14.6) & 0 & $19(6.5)$ \\
\hline
\end{tabular}

${ }^{a}$ Belgium, Germany, Spain, France, UK, Israel, and Italy. ${ }^{\mathrm{b}}$ Brazil. ${ }^{\mathrm{c}}$ Korea and Taiwan. ${ }^{\mathrm{d}}$ US. ${ }^{\mathrm{e}}$ South Africa. ${ }^{\mathrm{f}}$ Due to patient privacy rules. g Includes cleared or cured infections. ${ }^{\mathrm{h}}$ Problem joints were identified by investigators at baseline and were defined as joints with any of the following symptoms: chronic joint pain, chronic synovitis, haemophilic arthropathy, limited motion, or recurrent bleeding. HIV, human immunodeficiency virus; SD, standard deviation.

\subsection{Clinical Endpoints}

For the 6-Month Analysis Population, the median (range) follow-up time was 225.0 (169-469) days. In this observational study, FVIII treatment regimens were not assigned, and a wide spectrum of prophylactic models was adopted by each participating site. A high adherence to prescribed prophylaxis was observed, and pre-baseline and on-study adherence data were consistent. For the total study duration, median (range) adherence was $91.9 \%(27 \%-100 \%)$ of the derived prescribed frequency of their FVIII regimen. Adherence to $>80 \%$ of prescribed frequency was seen for $72.4 \%$ of participants $(163 / 225)$, while $<60 \%$ adherence was seen for $7.1 \%$ of participants $(16 / 225)$.

Overall, pre-baseline ABR data were consistent with on-study data. For the 6-Month Analysis Population, the median (range) ABR for treated bleeds for the total duration was $2.27(0,57.8)$; ABRs were $2.00(0,86.0)$ during pre-baseline and $1.85(0,37.8)$ on-study (Table 2). Results for treated bleeds by types of bleeds had a similar overall pattern to that of all treated bleeds. No bleeds were reported by $55(24 \%)$ participants.

Table 2. Pre-baseline and on-study annualised bleeding rates of the 6-Month Analysis Population.

\begin{tabular}{cccc}
\hline & $\begin{array}{c}\text { Pre-Baseline } \\
n=\mathbf{2 2 5}\end{array}$ & $\begin{array}{c}\text { On-Study } \\
\boldsymbol{n = 2 2 4}\end{array}$ & $\begin{array}{c}\text { Total Duration } \\
\boldsymbol{n}=\mathbf{2 2 4}\end{array}$ \\
\hline \multicolumn{2}{c}{ Annualised bleed rate, no. of bleeds/year } & & \\
All bleeds & & & \\
Mean (SD) & $5.34(10.1)$ & $4.81(6.83)$ & $5.04(7.53)$ \\
Median (range) & $2.00(0.0,94.0)$ & $2.05(0.0,37.8)$ & $2.61(0.0,62.7)$ \\
Treated bleeds & & & \\
Mean (SD) & $5.03(9.35)$ & $4.33(6.39)$ & $4.64(7.00)$ \\
Median (range) & $2.00(0.0,86.0)$ & $1.85(0.0,37.8)$ & $2.27(0.0,57.8)$ \\
\hline
\end{tabular}


Table 2. Cont.

\begin{tabular}{cccc}
\hline & $\begin{array}{c}\text { Pre-Baseline } \\
\boldsymbol{n = 2 2 5}\end{array}$ & $\begin{array}{c}\text { On-Study } \\
\boldsymbol{n}=\mathbf{2 2 4}\end{array}$ & $\begin{array}{c}\text { Total Duration } \\
\boldsymbol{n}=\mathbf{2 2 4}\end{array}$ \\
\hline Treated spontaneous & & & \\
bleeds & & & \\
Mean (SD) & $2.98(6.02)$ & $1.93(3.81)$ & $2.35(4.14)$ \\
Median (range) & $0.00(0.0,58.0)$ & $0.00(0.0,25.2)$ & $0.94(0.0,39.3)$ \\
Treated traumatic & & & \\
bleeds & $2.05(6.81)$ & $2.40(4.58)$ & $2.29(5.02)$ \\
Mean (SD) & $0.00(0.0,86.0)$ & $0.00(0.0,31.2)$ & $0.88(0.0,55.9)$ \\
Median (range) & & & \\
Treated joint bleeds & $3.74(7.67)$ & $2.74(4.68)$ & $3.19(5.41)$ \\
Mean (SD) & $2.00(0.0,72.0)$ & $1.21(0.0,25.5)$ & $1.44(0.0,47.0)$ \\
Median (range) & & & \\
Treated problem joint & & & $0.66(2.22)$ \\
bleeds & $1.22(3.69)$ & $0.00(0.0,20.0)$ & $0.00(0.0,21.4)$ \\
Mean (SD) & $0.00(0.0,32.0)$ & & \\
Median (range) & & &
\end{tabular}

SD, standard deviation.

The median (range) annualised FVIII utilisation rate for the 6-Month Analysis Population was 3680.9 (1359.1-13938.1) IU/ kg/year, and the median (range) annualised FVIII infusion rate was 122.3 (52.0-363.9) infusions/year across the total duration (Table 3). Annualised FVIII utilisation and infusion rates were similar during the pre-baseline and on-study periods. The greatest contributor to usage was usual prophylaxis.

Table 3. Pre-baseline and on-study annualised FVIII utilisation and infusion rates of the 6-Month Analysis Population.

\begin{tabular}{|c|c|c|c|}
\hline & Pre-Baseline & On-Study & Total Duration \\
\hline \multicolumn{4}{|l|}{$\begin{array}{l}\text { Mean (SD) annualised FVIII } \\
\text { utilisation rate, IU/kg/year }\end{array}$} \\
\hline$n$ & 223 & 222 & 222 \\
\hline All uses & 3937.9 (1799.7) & $3927.7(1768.1)$ & $3928.5(1698.2)$ \\
\hline \multicolumn{4}{|l|}{ Subtypes of usage } \\
\hline Bleeds & $261.9(489.0)$ & $186.7(287.4)$ & $219.2(330.7)$ \\
\hline Surgery/procedures & $67.1(411.4)$ & $57.5(202.7)$ & $62.6(222.1)$ \\
\hline One-time prophylaxis ${ }^{a}$ & $32.9(154.6)$ & $19.2(68.9)$ & $25.5(82.0)$ \\
\hline Usual prophylaxis $\mathrm{b}$ & $3575.9(1756.9)$ & $3664.3(1685.4)$ & $3621.2(1637.8)$ \\
\hline \multicolumn{4}{|c|}{$\begin{array}{l}\text { Mean (SD) annualised FVIII } \\
\text { infusion rate, no. of infusions/year }\end{array}$} \\
\hline$n$ & 225 & 224 & 224 \\
\hline All uses & $130.5(45.2)$ & $131.5(48.5)$ & $131.1(45.2)$ \\
\hline \multicolumn{4}{|l|}{ Subtypes of usage } \\
\hline Bleeds & $8.19(15.6)$ & $5.99(8.91)$ & $6.94(10.3)$ \\
\hline Surgery/procedures & $1.75(9.78)$ & $1.72(7.12)$ & $1.77(6.15)$ \\
\hline One-time prophylaxis ${ }^{\text {a }}$ & $0.96(4.61)$ & $0.51(1.82)$ & $0.71(2.34)$ \\
\hline Usual prophylaxis ${ }^{b}$ & $119.6(46.8)$ & $123.3(48.5)$ & $121.6(46.3)$ \\
\hline
\end{tabular}

a Refers to a single infusion in anticipation for patients at high bleeding risk (e.g., before playing sports). ${ }^{\mathrm{b}}$ Refers to continuous or ongoing use aimed at maintaining FVIII activity above a certain target level. FVIII, Factor VIII; $\mathrm{SD}$, standard deviation.

\subsection{Patient-Reported Outcomes}

For 289/294 (98.3\%) participants in the total population, the Haemo-QoL-A median (range) Total Score was 76.3, (9.4-100), with higher scores representing better health-related QoL (Figure 2A). The highest domain scores were observed for Emotional Impact, Role Functioning, and Worry, while the lowest scores were observed for Physical Functioning and Consequences of Bleeding. 

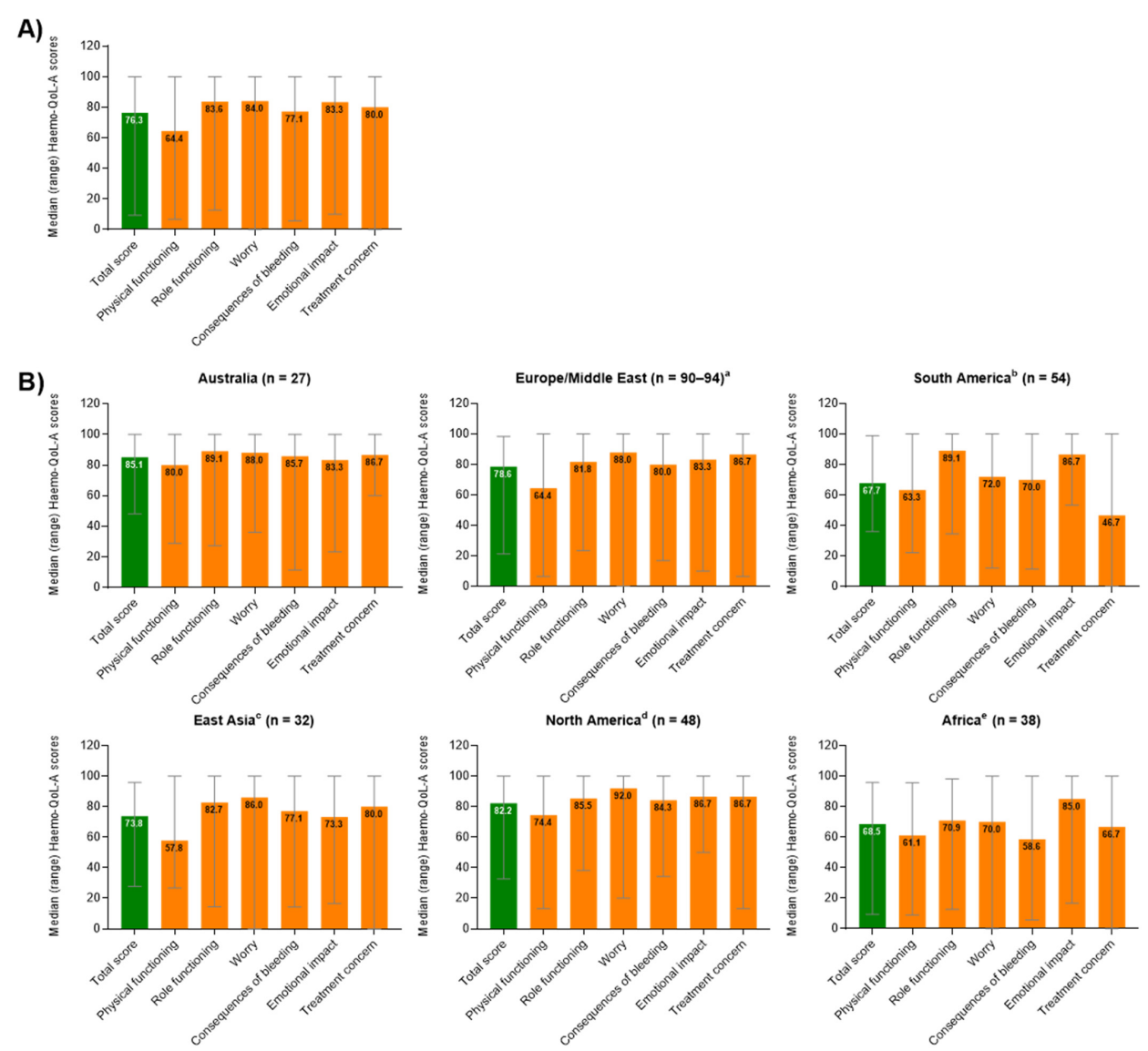

Figure 2. Median (range) overall transformed Haemo-QoL-A total and domain scores at baseline (A) for all participants globally $(n=298)$ and $(\mathbf{B})$ for participants by region. Haemo-QoL-A scores range from 0 to 100, with higher scores indicating higher quality of life. ${ }^{a}$ Belgium, Germany, Spain, France, UK, Israel, and Italy. For total score, $n=90$; Physical functioning, $n=94$; Role functioning, $n=94$; Worry, $n=91$; Consequences of bleeding, $n=93$; Emotional impact, $n=91$; Treatment concern, $n=94 .{ }^{\mathrm{b}}$ Brazil. ${ }^{\mathrm{c}}$ Korea and Taiwan. ${ }^{\mathrm{d}}$ US. ${ }^{\mathrm{e}}$ South Africa. Haemo-QoL-A, haemophilia-specific health-related quality of life questionnaire for adults; SD, standard deviation.

The EQ-5D-5L index was completed by 264/294 (89.8\%) participants, and the median (range) score was 0.767 (0.06-1.00). For all 294 enrolled participants, the median (range) score on the Visual Analog Scale (VAS) portion of the EQ-5D-5L was 80.0 (20.0-100.0). The median (range) HAL summary score for 293/294 (99.7\%) participants was 80.5 (20.5-100.0) points, with higher scores representing better self-perceived functional abilities. For 289/294 (98.3\%) participants, the median (range) WPAI+CIQ:HS Activity Impairment percentage score was $20.0 \%(0-90.0 \%)$, with higher percentages indicating greater impairment and less productivity. Most participants (286/294, 97.3\%) completed their diary entries, with a median (range) of 28.5 (1.0-95.0) weeks of data collected. The median (range) percentage of missed days from work (calculated as missed days/expected workdays) for the total population was $0 \%(0-100 \%)$.

\subsection{Comparative Analysis among Trial Sites by Region}

At enrolment, the median age was lowest among participants in South America (27 years) and highest among participants from East Asia (40 years); the median weight was highest among participants from North America $(77.5 \mathrm{~kg})$, South America $(78.1 \mathrm{~kg})$, and Australia $(79.0 \mathrm{~kg}$ ) (Table 1). Rates of problem joints were highest among participants from East Asia (56.3\%) and lowest among those from South America (9.3\%) and Africa (18.4\%). Exclusive EHL product use was highest among participants in Australia, followed by Europe/Middle East and North America (Figure S1). Plasma-derived products were 
primarily used by participants in Africa, while participants from the sites in East Asia generally either exclusively used SHL products or used a combination of FVIII product types during the study period (also including participants who switched products).

For most regions, pre-baseline and on-study ABR for treated bleeds were consistent (Table S1). A high degree of variability was noted in participants from East Asia during the pre-baseline period, but variation was lower during the on-study period. On-study median ABRs were highest in participants from the African sites (4.25) and lowest for participants at the South American (0.00) and Australian sites (1.68).

In all sites, FVIII utilisation rates were generally similar pre-baseline and on-study across FVIII products (Table S2). Participants in Africa reported the least FVIII use, followed by participants in South America and East Asia; participants in North America, followed by Australia and Europe/Middle East, reported the most.

On-study annualised infusion rates were consistent with pre-baseline values across regions (Table S3). Infusion rates for participants in North America were similar to those from sites in Australia and Europe/Middle East, with the highest infusion rates reported for participants at sites in South America.

Median Haemo-QoL-A total scores ranged from 85.1 for participants from sites in Australia to 67.7 for participants from sites in South America (Figure 2B). The most impacted domain was Physical Functioning in all regional groups except for South America and Africa. In South America, Treatment Concern (e.g., "I worry about the availability of haemophilia products") had the lowest domain score, while in Africa, Consequences of Bleed (e.g., "I worry about accidents") was the most impacted domain.

\subsection{Safety}

The incidence of AEs in the total population $(n=294)$ was $43.5 \%$; no AEs led to study discontinuation (Table S4). The most common haemophilia-related AEs were arthralgia $(5.8 \%)$, haemophilia arthropathy $(2.0 \%)$, back pain $(1.7 \%)$, and musculoskeletal pain $(1.4 \%)$. SAEs were reported in $14(4.8 \%)$ participants. No particular pattern of SAEs was noted; 5 SAEs were Grade 3 bleeding or haemophilia-related events, including haemorrhoidal haemorrhage $1(0.3 \%)$, haemophilic arthropathy $1(0.3 \%)$, oesophageal haemorrhage $1(0.3 \%)$, haematuria $1(0.3 \%)$, and haematoma $1(0.3 \%)$.

\section{Discussion}

In this study, we present real-world data on bleeding, FVIII use, and QoL in a global cohort of participants with severe haemophilia A potentially interested in enrolling in a gene therapy trial. These data reflect a severe HA population receiving regular FVIII prophylaxis treatment. At baseline, a high proportion of participants reported joint-related comorbidities of haemophilia. Joint-related procedures, such as arthroplasty, were also common, confirming that this severe haemophilia population is more likely to have joint problems and need associated surgery at a younger age.

$\mathrm{ABR}$ and FVIII usage results in the pre-baseline period were generally similar to the on-study period, indicating reliability of retrospective data. For unknown reasons, a slight increase in treated traumatic bleeds on-study compared to pre-baseline was observed. However, this study was not powered for a statistical analysis comparing retrospectively and prospectively collected data. Additional research is needed to further evaluate the change in treated traumatic bleed rates observed here.

Our data are similar to previous reports of real-world bleeding and FVIII use in individuals with severe haemophilia A. In a global, noninterventional study that prospectively collected real-world data of 49 participants with severe HA treated with prophylactic FVIII, the mean $(95 \%$ confidence interval) and median $(\mathrm{Q} 1, \mathrm{Q} 3)$ ABRs were $5.0(3.3,7.5)$ and $1.9(0.0,0.82)$ for treated bleeds and $6.2(4.2,9.2)$ and $2.7(0.0,9.4)$ for all bleeds, respectively; the majority $(83.7 \%)$ of participants received SHL prophylaxis [18]. Adherence to proscribed prophylaxis frequency was lower in that study than here, with $66.7 \%$ of participants reporting adherence to $>80 \%$ of prescribed doses [18]. In another study enrolling 18 severe HA 
participants, the median baseline ABR for all bleeds was 7.5 (range: 4-28) and the median annualised FVIII utilisation was $3028 \mathrm{IU} / \mathrm{kg} / \mathrm{yr}$ [19]. A large 12-month retrospective study involving 1346 males from seven European countries, mostly receiving regular prophylaxis (75\% with severe HA) [4], reported comparable median (Q1, Q3) ABR values ranging from $1.0(0,2)$ to $4.0(1,12)$ for all bleeds and from $0.0(0,1)$ to $2.5(1,6)$ for joint bleeds. Similarly, an Austrian haemophilia registry study reported median (IQR) ABRs of 4.9 (1.6, 13.5) for all bleeding events and $4.1(0.9,12.3)$ for joint bleeding in 26 participants with severe HA receiving FVIII prophylaxis; the median (Q1, Q3) annualised FVIII utilisation was $3364(2219,4297) \mathrm{IU} / \mathrm{kg} / \mathrm{yr}$ [20]. Overall, our data combined with these previous results suggest that breakthrough bleeding events requiring additional treatment occur for many individuals with severe HA receiving FVIII prophylaxis.

The QoL and PRO results from this study indicate substantial burden and impairments in this population despite good adherence to a variety of prophylactic treatment regimens. Health-related QoL was particularly impacted in the Physical Functioning domain, reflecting the residual burden of disease. The median Haemo-QoL-A total scores (76.3) in our study tended to be lower (indicating worse QoL) than those previously reported in small US ( $n=21$; mean, 85.6) [21] and Canadian $(n=33$; mean, 85.8$)$ [22] cohorts $(100 \%$ and $93 \%$ with severe HA, respectively) but similar to those reported in an international cohort ( $n=221$; mean, $73.1 ; 52 \%$ with severe HA) [8], a discrepancy most likely due to the younger age and fewer comorbidities observed in the US and Canadian cohorts $[8,22]$. However, our median baseline EQ-5D and EQ VAS scores (0.767 and 80.0, respectively) were consistent with those from a single-centre UK study enrolling 44 patients with severe HA (mean (range) EQ-5D-5L, 0.68 (0.09-1) and HAL, 71.7 (30-100) scores) [23]. Importantly, the EQ-5D-5L may underestimate QoL burden in haemophilia due to the disability paradox reported in this population [24]. Lastly, perceived level of overall impairment due to HA as measured with the WPAI+CIQ:HS was rated as 30\% in an observational multicentre study conducted in Italy (84 patients, $86 \%$ with severe HA) [25], slightly higher than that found in our study (24\%).

When comparing trial sites grouped by geographic region, ABRs were highest at sites in East Asia and in Africa; these sites were also among those with the lowest FVIII utilisation in this study. Though Africa and East Asia comprise 39\% of the total population of all countries participating in the WFH global survey, they receive $4 \%$ of exogenous FVIII products [26], making the recommended implementation of prophylaxis difficult [27]. In our study, participants in East Asia and Africa reported much lower infusion rates with SHL and/or plasma-derived FVIII than elsewhere, consistent with limited FVIII availability in these regions [26]. Low FVIII utilisation was also reported at sites in South America, where limited FVIII supply $[26,28]$ may be partially mitigated by giving more frequent infusions, as the infusion rate there was the highest of any region in our study. The ABRs for participants in South America were similar to those reported here for developed regions. Interestingly, participants in Africa also reported low problem joint numbers but high ABRs. The comparatively low proportion of participants with problem joints in Africa and South America was unexpected given the importance of early, consistent prophylaxis for reducing joint damage [3,29] and limited and/or recent access to prophylaxis in these regions $[28,30,31]$. Problem joints may have been underreported at these sites. Further study is needed to determine the accuracy of problem joint reporting outside of Europe, where the term was developed and validated.

Despite presenting the highest amount of FVIII utilisation, infusion rates for participants in North America were similar to those in Australia and Europe/Middle East. The high median body weight of North American participants in this study compared to European/Middle Eastern participants may contribute to higher dosing per infusion, as dosing recommendations are weight based [3]; additionally, more frequent exclusive EHL use by participants in Australia vs North America (Figure S1) may explain the lower overall use of FVIII product, as switching from SHL to EHL prophylaxis reduces injection frequency [32].

Participants at sites in regions known to have limited access to FVIII products and thus lower utilisation—Africa, South America, and East Asia [26] — had worse Haemo- 
QoL-A outcomes than the ones in Australia, Europe/Middle East, and North America. For participants in both South America and Africa, Treatment Concern (e.g., "I worry about the availability of haemophilia products") had lower domain scores than other regions, reflective of the well-recognised issues in those regions [26,28,30,31,33]. For participants in Africa, Consequences of Bleed (e.g., "I worry about accidents") was the most impacted domain, possibly due to limited FVIII supply and a lack of haemophilia management education [30,31,34]. Overall, the observed differences between participants at trial sites grouped by region likely resulted from many confounding factors, including FVIII treatment regimens, type of FVIII used, access to treatment, and regional differences in education about haemophilia [35-37].

Overall, safety outcomes were consistent with other studies of individuals with severe HA $[18,38,39]$. AEs not related to HA observed during the on-study period were as expected for an otherwise healthy, young adult male population. The relatively high incidence of some AEs (such as arthropathy) reflects the underlying disease burden of HA.

Potential study limitations include visits scheduled at irregular intervals following the usual standard of care/routine clinical practice for the study site and the collection of QoL measures at a single time point. The population enrolled in this study was very heterogeneous in terms of age, race, medical history, and access to medical treatment, and it represents a specific cohort that is potentially interested in pursuing gene therapy for HA. This may have resulted in selection bias, as illustrated by the AAV5+ individuals who chose not to enrol after screening. Participants seeking better outcomes than those provided by their current FVIII prophylaxis may have been particularly motivated to enrol. Additionally, the mandated 6 months of high-quality retrospective data may have biased enrolment towards well-informed participants compliant with treatment. Site selection may also have been biased, as participating sites were chosen based on capability for gene therapy trials. Future studies that evaluate current prophylaxis therapies and clinical outcomes in developing countries are recommended to more fully characterize the state of haemophilia care worldwide.

\section{Conclusions}

Despite high prophylaxis adherence, the continued occurrence of spontaneous and joint bleeding events requiring treatment and impaired physical functioning was evident in our study. These results illustrate real-world shortcomings associated with regular FVIII prophylaxis for this cohort of individuals with severe HA, for whom additional haemostatic options are needed.

Supplementary Materials: The following are available online at https://www.mdpi.com/article/10.339 0/jcm10245959/s1, supplementary S1: Participating Sites and Investigators; supplementary S2: Methods; Figure S1: Participant FVIII prophylaxis product use by region in the 6-Month Analysis Population $(n=225) ;$ Table S1: Pre-baseline and on-study annualised treated bleeding rates of the 6-Month Analysis Population by region; Table S2: pre-baseline and on-study annualised FVIII utilisation rates of the 6-Month Analysis Population by region; Table S3: Pre-baseline and on-study annualised FVIII infusion rates of the 6-Month Analysis Population by region; Table S4: Overall incidence of AEs.

Author Contributions: G.K., Y.-C.C., G.L., C.P., H.T., A.v.D., M.T., M.R., J.O., M.E.M.-C., Y.-S.P., F.P., M.C.O. and J.M. were clinical investigators who carried out study procedures. J.Q. oversaw the quality-of-life analyses. M.H. performed the statistical analyses. D.B.R. and B.K. oversaw conduct of the clinical study and contributed to the study design. All authors contributed to the interpretation of the results and provided critical input during manuscript drafting. All authors have read and agreed to the published version of the manuscript.

Funding: This study was sponsored by BioMarin Pharmaceutical Inc. (Novato, CA, USA).

Institutional Review Board Statement: This study was conducted in compliance with local regulations, the International Conference on Harmonisation Guidelines for Good Clinical Practice, and the Declaration of Helsinki. The ethics committees or institutional review boards of participating sites reviewed and approved the protocol (4642-17-SMC). 
Informed Consent Statement: All participants provided written informed consent prior to enrolment.

Data Availability Statement: De-identified individual participant data underlying these results will be made available together with the clinical protocol and data dictionaries, for non-commercial, academic purposes. Additional supporting documents may be available upon request. Investigators will be able to request access to these data and supporting documents via the Publication Data Request page at www.BioMarin.com (accessed on 14 December 2021) beginning 6 months and ending 2 years after publication. Data associated with any ongoing development program will be made available within 6 months after approval of the relevant product. Requests must include a research proposal clarifying how the data will be used, including the proposed analysis methodology. Research proposals will be evaluated relative to publicly available criteria available at www.BioMarin.com (accessed on 14 December 2021) to determine if access will be given, contingent upon the execution of a data access agreement with BioMarin Pharmaceutical Inc.

Acknowledgments: We thank the study participants, study site personnel, and investigators contributing to the 270-902 study. Assistance in medical writing and editorial support were provided by Kathleen Pieper and Elisabetta Lauretti of AlphaBioCom, LLC, and funding was provided by BioMarin Pharmaceutical Inc. Project management support was provided by Sara Hawley of BioMarin Pharmaceutical Inc.

Conflicts of Interest: Gili Kenet reports research support from Alnylam, Bayer, Opko Biologics, Pfizer, and Shire, as well as honoraria for consultancy from Alnylam, Bayer, Novo Nordisk, Pfizer, Roche, and Takeda. Yeu-Chin Chen, Gillian Lowe, Charles Percy, Huyen Tran, and Young Shil Park report nothing to disclose. Marc Trossaërt reports research support from Takeda, CSL Behring, Novo Nordisk, and SOBI, as well as consulting honoraria from Takeda, CSL Behring, and Roche. Annette von Drygalski has received fees from BioMarin, Bioverativ/Sanofi Genzyme, Novo Nordisk, Pfizer, Takeda, and UniQure for participation in industry-sponsored education events and advisory boards. She is cofounder and a member of the board of directors of Hematherix Inc. She holds a patent for a super FVa and is the inventor and physician lead for the Joint Activity and Damage Examination (JADE) ultrasound measurement tool. The JADE measurement tool is copyrighted and is commercialised through a partnership between the University of California, the University of San Diego School of Medicine, and the Hemophilia and Thrombosis Treatment Center at the University of San Diego, California, of which she is medical director. Mark Reding reports receiving honoraria for participation on advisory boards and/or speakers bureaus from Bayer, CSL Behring, Novo Nordisk, Sanofi Genzyme, and Takeda, as well as grant funding from Bayer and BioMarin Pharmaceutical Inc. Johannes Oldenburg has received reimbursements for attending symposia/congresses, honoraria for speaking or for consulting, or funds for research from Bayer, Biogen Idec, Biotest, Chugai, CSL Behring, Grifols, Novo Nordisk, Octapharma, Pfizer, Roche, Shire, and SOBI. Maria MingotCastellano reports receiving honoraria for consulting or lecturing for Novo Nordisk, Grifols, Baxter, and Wyeth. Flora Peyvandi reports receiving honoraria as a speaker for educational symposia by Grifols, Sanofi, and Takeda and advisory member for Sanofi and Roche. Margareth C Ozelo reports consulting payments from Bayer, BioMarin Pharmaceutical Inc., Novo Nordisk, Pfizer, Roche, Sanofi, and Takeda; research grants from Pfizer, Roche, and Takeda; participation as a clinical trial investigator for BioMarin Pharmaceutical Inc., Novo Nordisk, Pfizer, Roche, Sanofi, and Takeda; speaker fees/payments from Bayer, BioMarin Pharmaceutical Inc., Novo Nordisk, Roche, and Takeda; travel support from Novo Nordisk, Roche, and Takeda; and participation in grant review for Grifols. Johnny Mahlangu reports consulting payments from Baxalta, Catalyst BioSciences, CSL Behring, Freeline, LFB, Novo Nordisk, and Spark; research grants from BioMarin Pharmaceutical Inc., CSL Behring, Novartis, Novo Nordisk, Pfizer, Roche, Sanofi, Sobi, and UniQure; participation as a clinical trial investigator for BioMarin Pharmaceutical Inc., CSL Behring, Novartis, Novo Nordisk, Pfizer, Roche, Sanofi, Sobi, and UniQure; receiving speaker fees/payments from Novo Nordisk, Pfizer, Roche, Sanofi, Shire, Sobi, Takeda, ISTH, and WFH; and travel support from ISTH, Novo Nordisk, Pfizer, Roche, Sanofi, Shire, Sobi, Takeda, and WFH. Jennifer Quinn and Divya B Reddy are employees and stockholders of BioMarin Pharmaceutical, Inc. Mei Huang and Benjamin Kim are former employees of BioMarin Pharmaceutical, Inc. and may hold stock. 


\section{References}

1. Iorio, A.; Stonebraker, J.S.; Chambost, H.; Makris, M.; Coffin, D.; Herr, C.; Germini, F. Establishing the Prevalence and Prevalence at Birth of Hemophilia in Males: A Meta-analytic Approach Using National Registries. Ann. Intern. Med. 2019, 171, 540-546. [CrossRef] [PubMed]

2. Blanchette, V.S.; Key, N.S.; Ljung, L.R.; Manco-Johnson, M.J.; Van Den Berg, H.M.; Srivastava, A. Definitions in hemophilia: Communication from the SSC of the ISTH. J. Thromb. Haemost. 2014, 12, 1935-1939. [CrossRef] [PubMed]

3. Srivastava, A.; Santagostino, E.; Dougall, A.; Kitchen, S.; Sutherland, M.; Pipe, S.W.; Carcao, M.; Mahlangu, J.; Ragni, M.V.; Windyga, J.; et al. WFH Guidelines for the Management of Hemophilia, 3rd edition. Haemophilia 2020, 26 (Suppl. 6), 1-158. [CrossRef] [PubMed]

4. Berntorp, E.; Dolan, G.; Hay, C.; Linari, S.; Santagostino, E.; Tosetto, A.; Castaman, G.; Álvarez-Román, M.; Lopez, R.P.; Oldenburg, J.; et al. European retrospective study of real-life haemophilia treatment. Haemophilia 2017, 23, 105-114. [CrossRef]

5. Stonebraker, J.S.; Brooker, M.; Amand, R.E.; Farrugia, A.; Srivastava, A. A study of reported factor VIII use around the world. Haemophilia 2010, 16, 33-46. [CrossRef] [PubMed]

6. Manco-Johnson, M.J.; Soucie, J.M.; Gill, J.C. Joint Outcomes Committee of the Universal Data Collection USHTCN. Prophylaxis usage, bleeding rates, and joint outcomes of hemophilia, 1999 to 2010: A surveillance project. Blood 2017, 129, $2368-2374$. [CrossRef] [PubMed]

7. Bulcha, J.T.; Wang, Y.; Ma, H.; Tai, P.W.L.; Gao, G. Viral vector platforms within the gene therapy landscape. Signal Transduct. Target. Ther. 2021, 6, 53. [CrossRef]

8. Rentz, A.; Flood, E.; Altisent, C.; Bullinger, M.; Klamroth, R.; Garrido, R.P.; Scharrer, I.; Schramm, W.; Gorina, E.; The Members of the Haemo-QoL-A Steering Committee. Cross-cultural development and psychometric evaluation of a patient-reported health-related quality of life questionnaire for adults with haemophilia. Haemophilia 2008, 14, 1023-1034. [CrossRef] [PubMed]

9. Haemo-QoL Study Group. Scoring Manual. Available online: http://haemoqol.de/scoring/manual/ (accessed on 15 December 2020).

10. The EuroQol Group. EuroQol-a new facility for the measurement of health-related quality of life. Health Policy 1990, 16, 199-208. [CrossRef]

11. Brooks, R.; EuroQol Group. EuroQol: The current state of play. Health Policy 1996, 37, 53-72. [CrossRef]

12. van Genderen, F.R.; Westers, P.; Heijnen, L.; de Kleijn, P.; van den Berg, H.M.; Helders, P.J.M.; van Meeteren, N.L.U. Measuring patients' perceptions on their functional abilities: Validation of the Haemophilia Activities List. Haemophilia 2006, 12, 36-46. [CrossRef]

13. Recht, M.; Neufeld, E.J.; Sharma, V.R.; Solem, C.T.; Pickard, A.S.; Gut, R.Z.; Cooper, D.L. Impact of Acute Bleeding on Daily Activities of Patients with Congenital Hemophilia with Inhibitors and Their Caregivers and Families: Observations from the Dosing Observational Study in Hemophilia (DOSE). Value Health 2014, 17, 744-748. [CrossRef] [PubMed]

14. Reilly Associates. WPAI Scoring. Available online: http://www.reillyassociates.net/WPAI_Scoring.html (accessed on 15 December 2020).

15. McLaughlin, P.; Hermans, C.; Asghar, S.; Burke, T.; Nissen, F.; Aizenas, M.; Meier, O.; Dhillon, H.; O’Hara, J. Problem Joints and Their Clinical and Humanistic Burden in Children and Adults with Moderate and Severe Hemophilia a: CHESS Paediatrics and CHESS II [abstract]. Blood 2020, 136 (Suppl. 1), 33-34. [CrossRef]

16. Burke, T.; Santana, I.R.; Chowdary, P.; Curtis, R.; Khair, K.; Laffan, M.; McLaughin, P.; Noone, D.; O’Mahony, B.; Pasi, J. Examination and Validation of a Patient-centric Joint Metric: "Problem Joint"; Empirical Evidence from the CHESS Paediatrics Dataset [abstract]. Res. Pract. Thromb. Haemost. 2021, 5 (Suppl. 1), 5-6.

17. Burke, T.; Santana, I.R.; Chowdary, P.; Curtis, R.; Khair, K.; Laffan, M.; McLaughin, P.; Noone, D.; O’Mahony, B.; Pasi, J. Examination and Validation of a Patient-Centric Joint Metric: "Problem Joint"; Empirical Evidence from the CHESS US Dataset [abstract]. Blood 2020, 136 (Suppl. 1), 25-26. [CrossRef]

18. Kruse-Jarres, R.; Oldenburg, J.; Santagostino, E.; Shima, M.; Kempton, C.L.; Kessler, C.M.; Lehle, M.; Chebon, S.; Bienz, N.S.; Asikanius, E.; et al. Bleeding and safety outcomes in persons with haemophilia A without in-hibitors: Results from a prospective non-interventional study in a real-world setting. Haemophilia 2019, 25, 213-220. [CrossRef] [PubMed]

19. Sun, H.; McIntosh, K.A.; Squire, S.J.; Yang, M.; Bartholomew, C.; Gue, D.S.; Camp, P.G.; Jackson, S.C. Patient powered prophylaxis: A 12-month study of individualized prophylaxis in adults with severe haemophilia A. Haemophilia 2017, 23, 877-883. [CrossRef] [PubMed]

20. Ay, C.; Perschy, L.; Rejtö, J.; Kaider, A.; Pabinger, I. Treatment patterns and bleeding outcomes in persons with severe hemophilia A and B in a real-world setting. Ann. Hematol. 2020, 99, 2763-2771. [CrossRef] [PubMed]

21. Manco-Johnson, M.J.; Sanders, J.; Ewing, N.; Rodriguez, N.; Tarantino, M.; Humphries, T.; TEEN/TWEN Study Group. Consequences of switching from prophylactic treatment to on-demand treatment in late teens and early adults with severe haemophilia A: The TEEN/TWEN study. Haemophilia 2013, 19, 727-735. [CrossRef] [PubMed]

22. St-Louis, J.; Urajnik, D.J.; Ménard, F.; Cloutier, S.; Klaassen, R.J.; Ritchie, B.; Rivard, G.E.; Warner, M.; Blanchette, V.; Young, N. Generic and disease-specific quality of life among youth and young men with Hemophilia in Canada. BMC Hematol. 2016, 16, 13. [CrossRef] [PubMed]

23. Taylor, S.; Room, J.; Barker, K. Physical activity levels in men with Haemophilia-A single centre UK survey. Haemophilia 2020, 26, 718-725. [CrossRef] [PubMed] 
24. O'Hara, J.; Martin, A.P.; Nugent, D.; Witkop, M.; Buckner, T.W.; Skinner, M.W.; O’Mahony, B.; Mulhern, B.; Morgan, G.; Li, N.; et al. Evidence of a disability paradox in patient-reported outcomes in haemophilia. Haemophilia 2021, 27, 245-252. [CrossRef]

25. Di Minno, G.; Santagostino, E.; Morfini, M.; Ettorre, C.; Cultrera, D.; Baldacci, E.; Russo, E.; Gallucci, C. Patient satisfaction and acceptability of an on-demand and on-prophylaxis device for factor VIII delivery in patients with hemophilia A. Patient Prefer. Adherence 2019, 13, 233-240. [CrossRef] [PubMed]

26. Stonebraker, J.S.; Bolton-Maggs, P.H.B.; Brooker, M.; Evatt, B.; Iorio, A.; Makris, M.; O’Mahony, B.; Skinner, M.W.; Coffin, D.; Pierce, G.F.; et al. The World Federation of Hemophilia Annual Global Survey 1999-2018. Haemophilia 2020, 26, 591-600. [CrossRef]

27. Bleeding disorders: Making strides towards treatment for all. Lancet Haematol. 2020, 7, E551. [CrossRef]

28. Guedes, V.G.; Thomas, S.; Wachholz, P.A.; Souza, S.A.L. Challenges and perspectives in the treatment of patients with haemophilia in Brasil. Rev. Assoc. Med. Bras. (1992) 2018, 64, 872-875. [CrossRef]

29. Manco-Johnson, M.J.; Lundin, B.; Funk, S.; Peterfy, C.; Raunig, D.; Werk, M.; Kempton, C.L.; Reding, M.T.; Goranov, S.; Gercheva, L.; et al. Effect of late prophylaxis in hemophilia on joint status: A randomized trial. J. Thromb. Haemost. 2017, 15, 2115-2124. [CrossRef] [PubMed]

30. Diop, S.; Haffar, A.; Mahlangu, J.; Chami, I.; Kitchen, S.; Pierce, G. Improving access to hemophilia care in sub-Saharan Africa by capacity building. Blood Adv. 2019, 3 (Suppl. 1), 1-4. [CrossRef] [PubMed]

31. Lambert, C.; Meité, N.; Sanogo, I.; Lobet, S.; Adjambri, E.; Eeckhoudt, S.; Hermans, C. Haemophilia in Côte d'Ivoire (the Ivory Coast) in 2017: Extensive data collection as part of the World Federation of Hemophilia's twinning programme. Haemophilia 2019, 25, 236-243. [CrossRef] [PubMed]

32. Brennan, Y.; Parikh, S.; McRae, S.; Tran, H. The Australian experience with switching to extended half-life factor VIII and IX concentrates: On behalf of the Australian Haemophilia Centre Directors' Organisation. Haemophilia 2020, 26, 529-535. [CrossRef]

33. Guedes, V.G.; Thomas, S.; Farrugia, A.; Wachholz, P.A.; Souza, S.A.L. Perspectives on haemophilia access in Brazil? Haemophilia 2018, 24, e255-e256. [CrossRef] [PubMed]

34. Mahlangu, J.N.; Naidoo, Y.; Goga, Y.; Vaithlingum, M.; Joubert, J.; Sutton, C.; Potgieter, J.; Cruickshank, A.-L.; Iorio, A. Home therapy for inherited bleeding disorders in South Africa: Results of a modified Delphi consensus process. S. Afr. Med. J. 2019, 109, 639-644. [CrossRef] [PubMed]

35. James, P.; Kasthuri, R.; Kruse-Jarres, R.; Soni, A.; Kulkarni, R.; Bidlingmaier, C.; Chitlur, M.; Fogarty, P.; Gomez, K.; Holm, P.A.; et al. Global Emerging HEmophilia Panel (GEHEP): A Multinational Collaboration for Advancing Hemophilia Research and Treatment. Transfus. Med. Hemother. 2013, 40, 352-355. [CrossRef] [PubMed]

36. Gupta, N.; Benbouzid, A.; Belhani, M.; El Andaloussi, M.; Maani, K.; Wali, Y.; El Fegoun, S.B.; Saad, H.A.; Mahlangu, J. HAEMOcare: The First International Epidemiological Study Measuring Burden of Hemophilia in Developing Countries. TH Open 2019, 3, e190-e199. [CrossRef] [PubMed]

37. O'Mahony, B.; Black, C. Expanding Hemophilia Care in Developing Countries. Semin. Thromb. Hemost. 2005, 31, 561-568. [CrossRef] [PubMed]

38. Nolan, B.; Mahlangu, J.; Perry, D.; Young, G.; Liesner, R.; Konkle, B.; Rangarajan, S.; Brown, S.; Hanabusa, H.; Pasi, K.J.; et al. Long-term safety and efficacy of recombinant factor VIII Fc fusion protein (rFVIIIFc) in subjects with haemophilia A. Haemophilia 2016, 22, 72-80. [CrossRef] [PubMed]

39. Shapiro, A.D.; Schoenig-Diesing, C.; Silvati-Fidell, L.; Wong, W.Y.; Romanov, V. Integrated analysis of safety data from 12 clinical interventional studies of plasma- and albumin-free recombinant factor VIII (rAHF-PFM) in haemophilia A. Haemophilia 2015, 21, 791-798. [CrossRef] 